\title{
R \\ Reflexiones sobre la necesaria cooperación entre administraciones en la Gestión del Patrimonio
}

\section{Ignacio Henares Cuéllar} Historia del Arte Universidad de Granada.
Catedrático de

Existe una realidad política y socio-cultural plenamente positiva, la gestión autonómica del Patrimonio andaluz tras el proceso de transferencia y la institucionalización de un modelo avanzado de tutela, desarrollado a través de una amplia práctica normativa, administrativa y técnica. Es necesario mantener el mandato constitucional y los principios de la legislación especial sobre Patrimonio histórico, la responsabilidad pública de su conservación, garantía de accesibilidad y fomento, el prevalente interés social implicado en los bienes culturales, cuya protección es el objeto de la tutela. La consideración de esta dimensión es la que permite percibir en el Patrimonio histórico niveles y aspectos esenciales a considerar y actuar, su naturaleza axiológica de valor colectivo, su carácter socio-jurídico de derecho fundamental, de instrumento para la cualificación de la vida humana, valor económico irreproducible e irremplazable, generador de plusvalías sociales, etc.

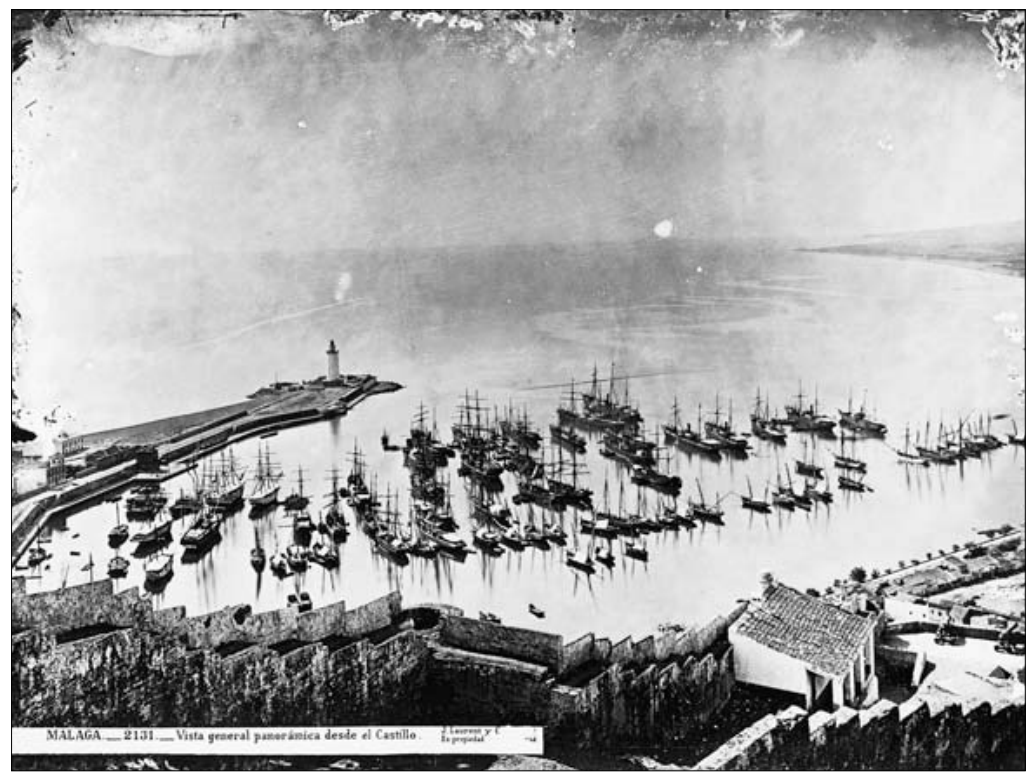
J. Laurent y Cía la las reduzca al mero ejercicio de una acción tuitiva y administrativa, o en el peor de los casos a una forma menor de beneficencia, en lugar de una práctica cuyo objeto es la protección y disfrute de bienes de titularidad social, que conciernen al conjunto de la sociedad andaluza y sus intereses, y que representan desde el punto de vista material y espiritual un horizonte imprescindible de progreso y sociabilidad definido al máximo nivel constitucional.

En este sentido trascendente del Patrimonio es en el que se debe propiciar la máxima implicación de agentes sociales y recursos de la Comunidad en torno a la tutela, por ello debe entenderse fundamentalmente como una necesidad un Plan Sectorial de la Junta de Andalucía cuyo objeto es la gestión de los bienes culturales. Situar en lugar eminente la idea de la necesaria cooperación entre las distintas administraciones en torno a un objeto y unos modelos de actuación que implican a ámbitos diversos desde el punto de vista económico, técnico o administrativo. La propuesta persigue, por otra parte, una finalidad de desarrollo económico y social a partir de la correcta puesta en valor de los bienes culturales. Tal finalidad es consecuente con una tradición bastante extensa en la doctrina de la tutela, la normativa y las cartas internacionales ya se trate de una práctica del Consejo de Europa o la UNESCO o las sucesivas reuniones de las Conferencias de Jefes de Estado de América Latina, que es la de vincular el Patrimonio al desarrollo humano y armónico en el interior de las sociedades democráticas. Nada que ver con un planteamiento puramente desarrollista, la idea de desarrollo sostenible pasa por el máximo respeto a la substantividad del Patrimonio y la consideración de una esencial búsqueda de la rentabilidad cualitativa, sociocultural y educativa por encima de cualquier rentabilidad exclusivamente económica.

Una tesis esencial sería la que derivaría del modelo de gestión medioambiental, de tan amplia audiencia y consenso sociales, que consistiría en dejar de considerar el Patrimonio desde la perspectiva del coste público para considerarlo un activo esencial. A pesar de todo un sector importantísimo del empresariado, especialmente el dedicado a la promoción y cons-
Es imprescindible redimensionar estas funciones y valores para evitar que descienda la exigencia social en torno al patrimonio y la falta de la deseable corresponsabilidad y participación en su gestión y tute- 


\section{La demanda municipal más generalizada es la que parte de la necesaria, y todavía insuficiente, cooperación entre las diversas Administraciones, con la finalidad de hacer eficaces social y económicamente los objetivos del planeamiento y evitar demoras en su cumplimiento, que acarrean riesgos para el patrimonio urbano e histórico.}

trucción, insiste en la inadecuación de las cautelas en el ámbito de la protección y en el quebranto de los intereses implicados en sus actividades empresariales, reclamando una acción de reconsideración legislativa y una redistribución de las cargas. En el debate sobre tutela, se discuten ambos aspectos considerando los implicados desde el punto de vista administrativo y técnico. La necesaria racionalización del uso de la normativa, el cumplimiento de las garantías que amparan el interés privado sin perjuicio de los bienes tutelados y la distribución de las cargas económicas generadas por la protección (costo de excavaciones arqueológicas en obras), siguiendo modelos que se contemplan en la Ley del suelo o en la normativa mediambiental. En todos los casos el planeamiento se considera el marco y el instrumento esencial para la regulación resolución de tales conflictos.

Continuar el importante diálogo con las Administraciones locales, responsables de la ejecución del planeamiento urbano y territorial, promotoras en los últimos años de la redacción de gran número de Planes especiales, que han mostrado actitudes mayoritariamente implicadas en la conservación del Patrimonio histórico. La demanda municipal más generalizada es la que parte de la necesaria, y todavía insuficiente, cooperación entre las diversas Administraciones, con la finalidad de hacer eficaces social y económicamente los objetivos del planeamiento y evitar demoras en su cumplimiento, que acarrean riesgos para el patrimonio urbano e histórico. Se insiste en la inmediata puesta en funcionamiento de la Mesa de Centros Históricos, que reúne con vistas a la ejecución de planes especiales a representantes de las distintas administraciones, proponiéndose la articulación de esta con las tareas de tutela previstas. Se reclama un protagonismo y responsabilidad más directos de las Diputaciones, cuyos Planes de Servicios resultan esenciales en la financiación de archivos y bibliotecas locales. La FAMP ha insistido en sus alegaciones en la necesidad de delegar funciones y responsabilidades en la gestión del Patrimonio en los municipios, según lo establecido en la LAPH de 1991. Es conveniente considerar la importancia del patrimonio gestionado por los municipios en archi- vos, museos y conjuntos municipales de los que son titulares, debiendo establecerse criterios de coordinación y colaboración entre las distintas Administraciones. Los funcionarios y técnicos municipales deberían tener acceso a la información y a los centros de investigación e información de la Junta.

En relación con la Iglesia Católica se parte en la actualidad de una valoración extraordinariamente positiva de la que ha sido un modelo de colaboración leal y eficaz en la década precedente, actuando a través de la Comisión Mixta Junta-Iglesia Católica, cuyas tareas se desea continuar y revitalizar por ambas partes. La filosofía expuesta por los representantes de la iglesia es de una gran modernidad, comprende el claro reconocimiento del valor social del Patrimonio, incluida su potencial contribución al desarrollo económico, muestra la disposición a que los bienes culturales de su titularidad cumplan el servicio público de su disfrute facilitando la accesibilidad, al tiempo que se reclama una mayor sensibilidad hacia los valores de culto que integran junto a los culturales la esencia del Patrimonio religioso. La experiencia significada por el Plan de Catedrales, entre las más representativas iniciativas desarrolladas en la tutela de aquel, ha constituido un modelo de gestión que se estima debe ser continuado en un régimen de cooperación y corresponsabilidad, priorizando las zonas más desfavorecidas y los bienes de mayor riesgo. Los eclesiásticos invocan el valor de una larga práctica de mantenimiento menos costosa que las grandes intervenciones, que coincide con la metodología de conservación preventiva.

Las Universidades andaluzas proponen diseñar unas relaciones que articulen la imprescindible colaboración entre la comunidad científica y la Administración cultural en una práctica social como la tutela. Existe una cierta frustración ante los límites y la falta de ejecución del convenio entre la Consejería de Educación y la de Cultura, que afecta en muchos casos a la conservación y difusión del propio Patrimonio Universitario. En un modelo I + D se hace imprescindible considerar e integrar en la gestión patrimonial a las entidades que representan la investigación básica y la innovación tecnológica. 